\title{
Mode of Action of Bronchodilating Drugs on Histamine-Induced Bronchoconstriction in Asthmatic Children
}

\author{
RICHARD KRAEMER, ${ }^{(44)}$ DENIS DUQUENNE, CHRISTIAN MOSSAY, AND FERNAND GEUBELLE
}

Clinical Physiology Laboratory, Department of Paediatrics, University of Liège, Liège, Belgium

\begin{abstract}
Summary
The bronchodilatory response of three $\beta_{2}$-agonists (fenoterol, salbutamol, and terbutaline), administered by a metered aerosol inhaler, was assessed in 19 asthmatic children after histamineinduced bronchoconstriction. At 1-min intervals, the changes in total pulmonary flow resistance $\left(R_{1}\right)$ and dynamic lung compliance (C dyn) were measured. After rank-ordering according to the base line value of $\mathrm{C}$ dyn (62 to $200 \%$ predicted), the patients were divided into two groups according to lung compliance: (1) patients with greater compliance (C dyn, 129 to $200 \%$ predicted) and (2) patients with lesser compliance ( $C$ dyn, 69 to $116 \%$ predicted). The effect of the three bronchodilators on the mean decrease of $R_{1}$ and on the increase of $\mathbf{C}$ dyn was studied and analyzed for each drug separately. In all patients, salbutamol was the most efficient bronchodilator of small airways $(P<0.02)$. The most striking feature of this $\beta_{2}$-mimetic was observed in patients whose lungs were initially overinflated (functional residual capacity over $120 \%$ predicted) but not obstructed before the histamine challenge ( $P$ $<0.005$ ). In these subjects $C$ dyn and $R_{1}$ are normalized after inhalation of salbutamol.

After fenoterol and terbutaline inhalation, obstruction of the large airways was not fully alleviated. In addition, these two drugs seemed not to affect the ventilatory asynchronism ( $C$ dyn alterations) in patients whose lungs had been overinflated before drug inhalation ( $\mathrm{C}$ dyn again around $150 \%$ predicted).
\end{abstract}

\section{Speculation}

On the basis of a distinction between patients with more or less compliant lungs, as defined by measurements of base line values of dynamic lung compliance, the search for optimal individual quantitative and qualitative response to one of the various bronchodilator drugs seems to be possible and of important therapeutic value. From the functional approach of asthmatic children during a symptom-free period and from the values of their lung volumes, total pulmonary flow resistance and dynamic lung compliance it would be possible to choose the most efficient bronchodilator.

The mainstay for bronchial asthma treatment is the use of drugs to alleviate airway obstruction or to prevent its development. The fundamental framework for diagnosis, grading of severity and pharmacologic management, was recently outlined by Ekwo and Weinberger (8). Other reviews on the effects of different bronchodilators and their mode of administration in asthmatic children have been published recently $(4,24,32-34)$. Administration of bronchodilator aerosols is a well-established treatment for airway obstruction in children with bronchial asthma $(1-8,14,22,27-30$, 39). Drugs which may be administered include atropine-like agents $(5,6,22)$ and, in order to minimize cardiac side-effects, selective $\beta_{2}$-sympathomimetics. Recent studies have demonstrated considerable differences in the preferential efficiency of these drugs on peripheral airways (42). It has been suggested $(5,6,18$,
$23,25,35)$ that in adult asthmatic patients, atropine-like substances predominantly dilate larger upstream airways and that $\beta_{2}$-sympathomimetics predominantly dilate smaller upstream airways.

The relative contribution made by large and small airways to flow limitation is of major interest to several research groups. This determination is important from the therapeutical point of view, since it is preferable to use a bronchodilating substance that specifically affects the area of broncho-obstruction in the particular patient.

There have been numerous studies on the effect of $\beta_{2}$-agonists in children. Little is known about their specific action on the small and/or large airways, especially the site of their action, since most of the published studies conducted lung function tests in the form of "forced breathing manoeuvres" $\left(\mathrm{FEV}_{1}=\right.$ forced expiratory volume $1 \mathrm{sec}, \mathrm{FVC}=$ forced vital capacity, $\mathrm{PF}=$ peak flow, FEF $=$ forced expiratory flow at different percent of the vital capacity). These tests fail to detect changes in small airway caliber. Moreover they are effort and cooperation-dependent.

The present study was, therefore, designed to ascertain whether the immediate bronchodilatory response of three $\beta_{2}$-sympathomimetic aerosols (fenoterol, salbutamol, and terbutaline) is similar in asthmatic children after histamine respiratory challenge and whether the preferential sites of action of these three drugs can be detected within the bronchial tree.

\section{PATIENTS AND METHODS}

Nineteen asthmatic children (10 boys and nine girls, aged between 5 and $17 \mathrm{yr}$ ) were studied after obtaining informed consent. All patients had a long history of moderate or mild asthma and all had positive skin tests for various pneumoallergens. No upper respiratory tract infection was observed in the $4 \mathrm{wk}$ before the study. No asthmatic attack had been noted in the preceding 14 days and the clinical examination was free of symptoms. No patient had been receiving oral or inhaled corticosteroids or antihistaminics for at least 10 days. Sodium cromoglycate was discontinued for at least 7 days and bronchodilators for at least 2 days. All patients had undergone pulmonary function tests before the assays and were thus familiar with the method applied. The lung function investigations included measurement of the functional residual capacity (FRC) using the closed helium dilution method, the lung volumes and capacities (residual volume, expiratory reserve volume, inspiratory capacity, and total lung capacity) (10). Dynamic lung compliance (C dyn) and total pulmonary flow resistance $\left(R_{1}\right)$ were measured by the usual methods $(12)$.

$\mathrm{C}$ dyn during normal frequency breathing was calculated from simultaneous volume and intraesophageal pressure changes at zero flow points between the start and the end of the inspiration. The pressure changes were measured with a differential pressure transducer (Elema-Schonander EMT 34) connected to an esophagel catheter the tip of which was covered by a balloon. The balloon (length, $8 \mathrm{~cm}$; circumference, $3 \mathrm{~cm}$; wall thickness, 0.05 $\mathrm{cm}$ ) was sealed over multiple perforations at the distal end of a 
polyethylene catheter (internal diameter $0.14 \mathrm{~cm}$ ) $100 \mathrm{~cm}$ long. It exerted zero pressure at a gas volume in the balloon of $0.3 \mathrm{ml}-$ the volume used for all measurements. The balloon was positioned through the nose in the midesophagus, in a position free from pressure artifacts (12). The volume displacement coefficient of the catheter-manometer system was about $0.002 \mathrm{ml} / \mathrm{cm} \mathrm{H} \mathrm{H}_{2} \mathrm{O}$, and the $90 \%$ response time $0.02 \mathrm{sec}$. Gas flow rate at the mouth was measured with a heated Fleisch pneumotachometer (no. 2) connected to a differential transducer. The intraesophageal pressure and the flow changes as well as the integrated volume values (Fenyves and Gut) were calibrated before each measurement and the response was linear over the range used. $R_{1}$ was calculated between inspiratory and expiratory mid-tidal-iso-volume points from the intraesophageal pressure and the simultaneously recorded flow curves.

Controlled bronchial inhalation tests were performed by the technique of Geubelle $(9,13,14,28,36,37)$ with histamine aerosols in order to appreciate bronchial hyperreactivity. During the inhalation of histamine aerosol and the subsequent 6 min after administration of the bronchodilator, the intraesophageal pressure and the flow and the volume changes of the lung were continuously recorded. An increase of $+100 \%$ in the intraesophageal recordings assessed by eye was considered an indication of a ventilatory obstruction and the inhalation of histamine was immediately discontinued. For ethical reasons only one histamine provocation test was performed on each patient. Consequently one bronchodilator had been randomly chosen for each patient assay and given from a metered aerosol inhaler $(2 \times 0.20 \mathrm{mg}$; $1.318 \mu$ mole fenoterol, $2 \times 0.10 \mathrm{mg} ; 0.835 \mu$ mole salbutamol, $2 \times$ $0.25 \mathrm{mg} ; 1.648 \mu$ mole terbutaline, respectively). All inhalations were performed during two deep inspirations followed by a few seconds of breathholding. All the lung function tests were performed between 9 AM and 12 o'clock during the winter months.

The statistical evaluation has been performed by WilcoxonMann-Whitney rank analysis.

\section{RESULTS}

\section{CLINICAL MATERIAL}

Before the Inhalation of the Histamine Aerosol. The anthropometric data of the patients, the values of their lung volumes and capacities expressed in percentage of the predicted values $(11,12)$ as well as the threshold doses of histamine determined by the provocation test (9) are collected in Table 1. The patients are rank ordered due to the base line value of the $\mathrm{C}$ dyn and divided into two groups.

All cases in group A fulfilled the following criteria: (1) the FRC is near the predicted value, (2) the $\mathrm{C}$ dyn is normal or decreased, and (3) the $R_{1}$ by the mean slightly increased.

Table 1. Anthropometric data, lung function base line value and histamine provocation threshold of the 16 asthmatic children, rank ordered according to the base line value of $C$ dyn

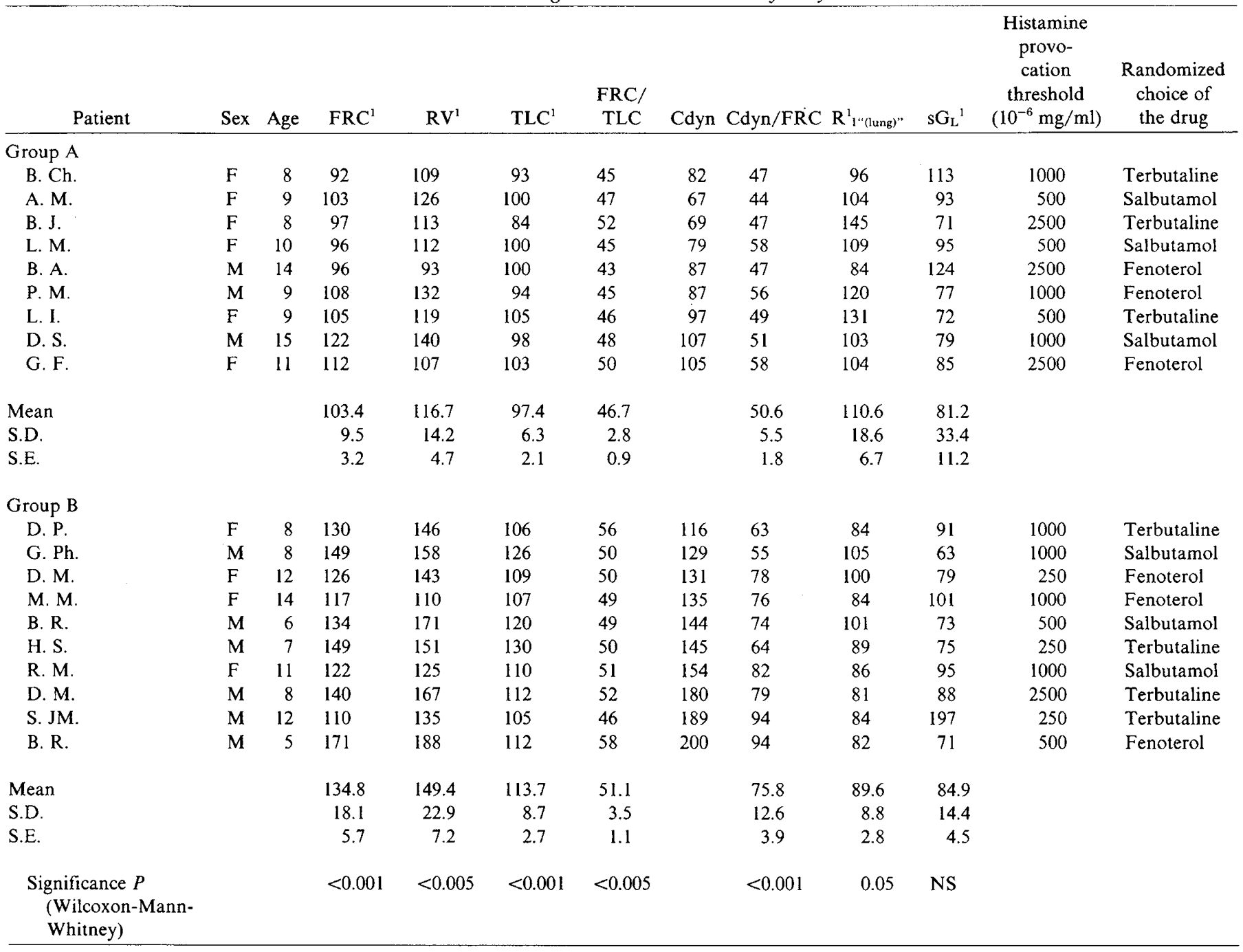

' $R V$, residual volume; TLC, total lung capacity; Cdyn and $R_{1}$ all parameters expressd in percentage of predicted values (11, 12). Significance level calculated according to the Wilcoxon-Mann-Whitney test; NS, not significant. 
Because gas is trapped in nonventilated lung units, the thoracic gas volume was not measured. It may be assumed that the lungs of this group were not significantly overinflated,

The ventilatory obstruction is demonstrated by the $R_{1}$ increase and a ventilatory asynchronism is indicated by the $\mathrm{C}$ dyn decrease. Both, large and peripheral airways are obstructed.

All cases of group B present the three following criteria: The FRC and the $C$ dyn are increased and $R_{l}$ is normal or decreased. A similar assumption concerning the possible trapped gas has to be considered. The ventilated lung units are hyperinflated and consequently the lung elastic recoil is increased. The pulling forces applied to the walls of the peripheral airways might explain the increase of the Cdyn: there is no obstruction of the peripheral airways and the specific compliance per litre of FRC is near the normal value in all cases.

Moreover, the distending forces are applied to the whole bronchial tree-the large as well as the more peripheral airways-and the resistance to the air flow is normal or, in most cases, below the predicted values.

The values of $R_{1}$ show a wide variation within the two groups, not inversely related to the values of $C$ dyn. Nevertheless, if the resistance is related to the concomitant lung volume and the specific conductance $\left(\mathrm{sG}_{\mathrm{L}}\right)$ is calculated it can be observed that the degree of impairment of the bronchial conductibility is about $20 \%$ in each group $\left(\mathrm{sG}_{\mathrm{L}} \%\right.$ pred.: group $\mathrm{A}: 74.2 \pm 9.8$ and group B: $87.2 \pm 13.7$, not significantly different). Also the $\mathrm{sG}_{\mathrm{L}}$ in the randomly selected drug subgroups is nearly equal $\left(\mathrm{sG}_{\mathrm{L}} \%\right.$ pred.: salbutamol $83.0 \pm 13.4$; terbutaline $88.3 \pm 17.1$; fenoterol $89.5 \pm$ 19.7).

The scattering of the base line values of $R_{1}$ and $C$ dyn demonstrates clearly, that even the so called "symptom-free interval" lung function abnormalities can be present, which are not detected clinically.

The difference betwen the values in groups A and B is statistically significant for FRC $(P>0.001)$, for residual volume $(P>$ $0.005)$, for total lung capacity $(P>0.001)$, for C dyn/FRC $(P>$ $0.001)$, and for $\mathrm{R}_{1}(P>0.05)$ (C dyn was taken as selection criterium).

After Inhalation of the Histamine Aerosol. The threshold doses of response to histamine is not significantly different in both groups $\mathrm{A}$ and $\mathrm{B}$.

Histamine induces a ventilatory obstruction of the large as well as of the small peripheral airways in both groups A and B. Indeed $R_{1}$ increases and $C$ dyn decreases. The $R_{1}$ increase, in percentage of the predicted value, is actually larger in group $B$ than in group A. But the $R_{1}$ values are similar in both groups after the respiratory challenge even if these values were in most cases lower than those predicted before the inhalation of histamine in group B.

Similarly, the drop of C dyn is larger in group B. But before the inhalation, $C$ dyn was lower in most cases of group A: in those patients whose small airway calibre was normal or subnormal, histamine induced an obstruction of the large as well as of the small airways.

The bronchoconstricting effect of histamine is short. It is thus impossible to determine the lung volumes and capacities on the top of a provocation, for such measurements require at least 10 min.

Response of the $\beta_{2}$-Mimetics. Table 2 and Figures 1 and 2 illustrate the $R_{1}$ and the $C$ dyn changes, respectively, after the inhalation of the $\beta$-mimetics.

Concerning the values of $R_{1}$ (indicating mostly the effect of the drugs on the large airways) the efficiency of the $\beta$-mimetics may be graded in the following way for both groups A and B: fenoterol, terbutaline and, the most efficient, salbutamol. In group $A$ these differences are smaller than in group B.

Concerning the values of $\mathrm{C}$ dyn (indicating mostly the effect of the drugs on the small airways) the "obstructed" patients of group A have to be separated from the "overinflated" subjects of group B.

In patients of group A, terbutaline and fenoterol have little effect on C dyn. Salbutamol inhalations induce an increase of $C$ dyn up to normal values. However, $R_{l}$ is still moderately increased

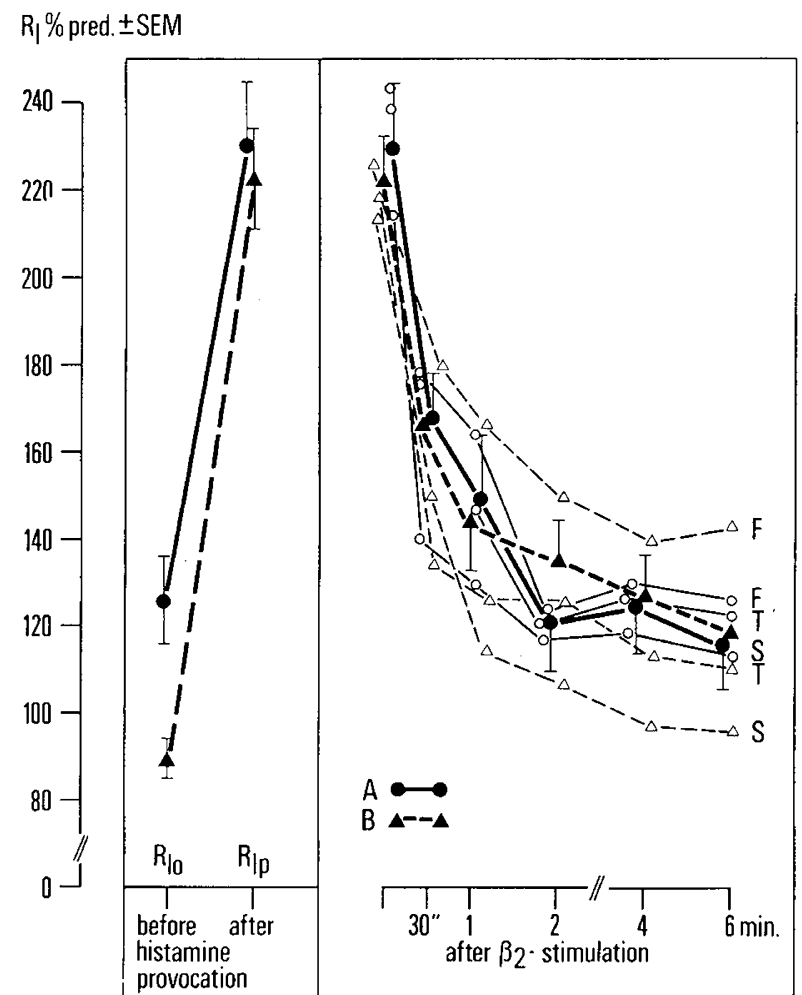

Fig. 1. Total resistance changes to the air flow in percentage predicted to the standard height (12) in the groups A (circles; initially normal inflated) and B (triangles; initially overinflated), before and after provocation, as well as in the next 6 min after administration of the $\beta_{2}$-agonists ( $F$, fenoterol; $T$, terbutaline, and $\mathrm{S}$, salbutamol). Open symbols represent the changes of the three treatment subgroups, closed symbols represent the mean values of groups $\mathrm{A}$ and $\mathrm{B}$.

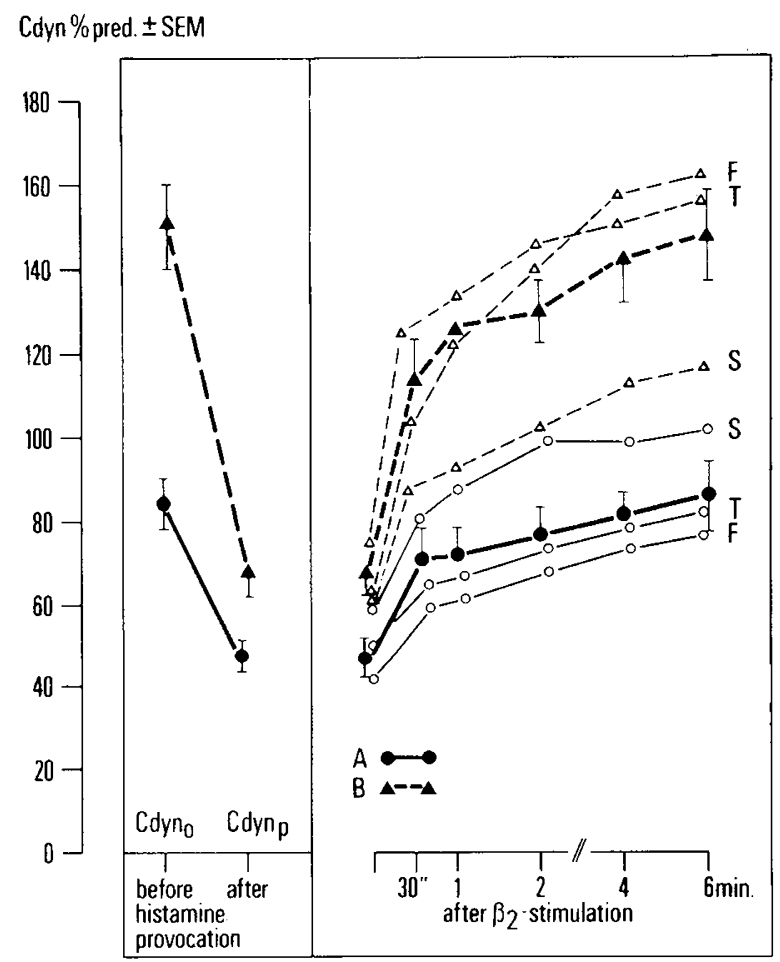

Fig. 2. C dyn changes in percentage predicted to the standard heights (12) in the group A (circles; initially normal ventilated) and B (triangles; initially overinflated), before and after provocation, as well as in the next $6 \mathrm{~min}$ after administration of the three $\beta_{2}$-agonists ( $\mathrm{F}$, fenoterol; $\mathrm{T}$, terbutaline; S, salbutamol). Open symbols represent the changes of the three treatment subgroups, closed symbols the mean values of groups $\mathrm{A}$ and $\mathrm{B}$. 


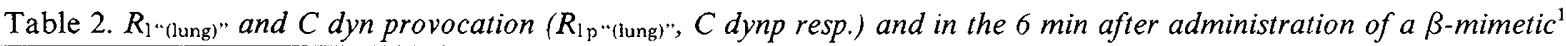

\begin{tabular}{|c|c|c|c|c|c|c|c|c|c|c|c|c|c|c|}
\hline $\mathrm{R}_{\mathrm{\jmath}} \mathrm{O}$ & $\mathrm{R}_{1} \mathrm{p}$ & \multicolumn{5}{|c|}{$\mathrm{R}_{1}$ after stimulation } & with: & C dyn & $C$ dyn $_{p}$ & \multicolumn{5}{|c|}{$\mathrm{C}$ dyn after stimulation } \\
\hline \multicolumn{15}{|c|}{ Group A } \\
\hline 104 & 195 & 125 & 96 & 94 & 92 & 80 & Salbutamol & 67 & 37 & 47 & 57 & 87 & 83 & 103 \\
\hline 145 & 256 & 218 & 184 & 174 & 177 & 174 & Terbutaline & 69 & 49 & 53 & 51 & 61 & 74 & 79 \\
\hline 109 & 262 & 162 & 140 & 143 & 133 & 133 & Salbutamol & 79 & 56 & 64 & 85 & 100 & 89 & 94 \\
\hline 131 & 296 & 164 & 149 & 109 & 112 & 109 & Terbutaline & 97 & 47 & 67 & 72 & 79 & 96 & 100 \\
\hline 103 & 222 & 101 & 116 & 103 & 106 & 108 & Salbutamol & 107 & 79 & 107 & 103 & 100 & 102 & 109 \\
\hline 104 & 193 & 189 & 164 & 130 & 148 & 144 & Fenoterol & 105 & 41 & 55 & 54 & 66 & 69 & 79 \\
\hline \multicolumn{15}{|c|}{ Group B } \\
\hline 84 & 177 & 147 & 106 & 87 & 91 & 94 & Terbutaline & 116 & 55 & 72 & 81 & 99 & 108 & 122 \\
\hline 89 & 199 & 131 & 124 & 126 & 115 & 96 & Terbutaline & 145 & 81 & 163 & 171 & 163 & 179 & 190 \\
\hline 86 & 184 & 151 & 116 & 114 & 106 & 105 & Salbutamol & 154 & 55 & 94 & 103 & 101 & 109 & 112 \\
\hline 81 & 215 & 156 & 160 & 158 & 164 & 100 & Terbutaline & 180 & 89 & 118 & 131 & 128 & 136 & 136 \\
\hline 84 & 250 & 158 & 130 & 125 & 113 & 102 & Terbutaline & 189 & 77 & 138 & 151 & 129 & 136 & 141 \\
\hline 82 & 214 & 184 & 161 & 139 & 127 & 140 & Fenoterol & 200 & 76 & 88 & 117 & 135 & 145 & 159 \\
\hline
\end{tabular}

'All values expressed as percentage of predicted values (12).

Table 3. Comparison between $I$ and II according to the nonparametric test of the rank-sum-analysis of Wilcoxon-MannWhitney

Statistical evaluation

Histamine-provocation test

\begin{tabular}{lrrc} 
& \multicolumn{3}{c}{ statistics } \\
Comparison between group A and $\mathrm{B}$ & $\mathrm{n}^{\mathrm{A}} / \mathrm{n}^{\mathrm{B}}$ & & $P$ \\
$\mathrm{R}_{1}$ increase in \% pred. & $9 / 10$ & 1.143 & $\mathrm{NS}^{1}$ \\
$\mathrm{C}$ dyn decrease in \% pred. & $9 / 10$ & 3.429 & $<0.001$
\end{tabular}

Drug response

measured by $R_{1}$ "(lung)"'-changes

group A:

Salbutamol/terbutaline/fenoterol

NS

group B:

Salbutamol/terbutaline

Salbutamol/fenoterol

Terbutaline/fenoterol

$\begin{array}{ccc}15 / 20 & 0.833 & \text { NS } \\ 15 / 15 & 3.671 & <0.0001 \\ 20 / 15 & 3.300 & <0.0004\end{array}$

measured by $\mathrm{C}$ dyn-changes

group A:

Salbutamol/terbutaline

Salbutamol/fenoterol

Terbutaline/fenoterol

$\begin{array}{ccc}15 / 15 & 2.011 & <0.022 \\ 15 / 15 & 2.883 & <0.002 \\ 15 / 15 & & \text { NS }\end{array}$

group B:

Terbutaline/salbutamol

Terbutaline/fenoterol

Fenoterol/Salbutamol

$\begin{array}{lll}20 / 15 & 2.600 & <0.005 \\ 20 / 15 & & \text { NS } \\ 15 / 15 & 3.587 & <0.0001\end{array}$

in this salbutamol-subgroup. One may assume that at the end of the assay these patients are not overinflated and that the obstruction of the small airways are alleviated even if a moderate obstruction of the large bronchi is still observed.

In patients of group B, terbutaline and fenoterol are immediately and significantly more efficient than salbutamol. Indeed the abnormally high values of Cdyn preexisting before the histamine inhalation, are observed after the administration of these two $\beta$ mimetics. One may assume that these patients are once again overinflated as before the assay: even if the large airways are still moderately obstructed $\left(R_{1}\right.$ being around $120 \%$ of the predicted values), the small bronchi are dilated (Cdyn being around $15 \%$ of the normal values).

At a first approach, salbutamol is less efficient than the two other $\beta$-mimetics: $C$ dyn does not increase up to the values observed before the histamine inhalation. But in this subgroup $R_{1}$ is decreased up to the predicted value. One may assume that the obstruction of the large bronchi is fully alleviated, and in addition these patients are no longer overinflated.

Table 3 gives a summary of the different statistical analyses. It becomes clear that the different response to salbutamol, namely in respect of $\mathrm{C}$ dyn changes, is the most pronounced.

\section{DISCUSSION}

Several recent studies concerning the mechanical factors involved in flow-limitation have demonstrated that conventional methods of detecting a ventilatory obstruction, such as measurement of pulmonary airway resistance to airflow, may fail to detect peripheral airway obstruction $(18,19,23,25,31,41)$. Moreover, forced breathing manoeuvres, such as forced vital capacities, forced expiratory volumes in $1 \mathrm{sec}$, and maximal flow volume curves require full cooperation from the subject, so the data obtained from children are less reproducible than those from trained adults $(10,15,16,40)$. In addition, attempts have been made to ascertain the decrease of Cdyn by increasing the respiratory frequency, assuming that this is a more sensitive method of detecting ventilatory obstruction of the small and peripheral airways $(19,26,41)$. This estimation of the frequency dependence of dynamic compliance also requires full cooperation from the patient and is therefore only of limited validity when performed on children. Moreover, the expiratory level (i.e., FRC) has to be known during this procedure $(10,26)$.

It is generally accepted that $R_{1}$ changes reflect mainly alterations in the dimensions of large airways (17), so that a decrease of $R_{1}$ after drug inhalation implies a dilation of these more central airways (e.g., the first 5 to 7 airway generations). In contrast, changes in $\mathrm{C}$ dyn are thought to be due to modifications in the 
more peripheral, small airways, leading to a ventilatory asynchronism (31).

Concerning these ventilatory abnormalities the inhalation of three bronchodilators is followed by a decrease in $\mathrm{R}_{1}$ and an increase in C dyn (Figs. 1 and 2).

In patients of group $\mathrm{A}$, the pathologic mechanism involved may be considered as an usual and classical pattern in asthmatic children during symptom-free period: little or no overinflation (the gas trapped in the lung not being considered in this appreciation), an increase of $R_{1}$ and a decrease of $C$ dyn, both large and small airways being moderately obstructed (20).

In patients of group $B$, these mechanisms have to be discussed. The ventilated units are overinflated, $R_{l}$ is decreased and $C$ dyn is increased: the higher the expiratory level, the higher the elastic forces are on the lung ( $\mathrm{C}$ dyn increase) and the pulling on the outer walls of the bronchi ( $R_{1}$ decrease) (21). But the primary cause of this overinflation is still disputed. It might be a sustained reflex response in some patients or a moderate bronchoconstriction, similar to the leveling on expiratory level at the start of a dyspnoeic attack. The effects of salbutamol in the patients of group B support this hypothesis. But in some overinflated patients the lung compliance seems to be abnormally high for the volume of the ventilated units. If the values of dynamic compliance might be confirmed by abnormally high values of the so-called static compliance and abnormally low intra-thoracic pressure for the expiratory level, one might assume that in a too compliant lung, the small and peripheral airways are almost collapsed at a normal lung volume: the leveling on expiratory level would be a reflex from these collapsed peripheral airways.

From the practical point of view the following conclusions may be suggested:

(1) From the values of the lung volumes, total pulmonary flow resistance, and $\mathrm{C}$ dyn, a distinction between patients with more or less compliant lungs can be made and consequently the different mode of action of the bronchodilating drugs individually estimated.

(2) If during a symptom-free period the patient is not usually overinflated and if large $\left(R_{1}\right.$ increase) and small ( $C$ dyn decrease) airways are obstructed, salbutamol is efficient on both types of bronchi, at least after an histamine provoked ventilatory obstruction. Salbutamol is a little more efficient that the two other $\beta$ stimulants, fenoterol and terbutaline, on the large bronchi but it is significantly more active on the small airways.

(3) In overinflated patients without obstruction of the airways, the small bronchi being distended by the increased lung elastic forces, fenoterol and terbutaline seem to fail efficacy on the provoked ventilatory obstruction with respect to small bronchi. One may assume that in a majority of such cases the lungs remain overinflated. However, in some cases, one may suspect a too compliant lung with concomitant ventilatory asynchronism.

In view of these considerations, the search for an individual optimal quantitative and qualitative response to a bronchodilator aerosol appears to be justified.

\section{REFERENCES AND NOTES}

1. Anderson, S. D.. Seale, J. P., Rozea, P., Bandler, L.. Theobald, G., and Lindsay D. A.: Inhaled and oral salbutamol in exercise-induced asthma. Am. Rev Respir. Dis., 114: 493 (1976).

2. Benjamin. C.: A comparative study of the bronchodilator of five $\beta_{2}$-adrenoreceptor stimulant drugs in patients with reversible bronchoobstruction. Med. Proc. 18: 35 (1972).

3. Davis, W. J., Mei Pang, L., Chernack, W. J., and Mellins, R. B.: Terbutaline in the treatment of acute asthma in childhood. Chest, 72: 614 (1977).

4. De Troyer, A., Yernault, J. C., and Rodenstein, D.: Influence of beta 2 -agonist aerosols on pressure-volume characteristics of the lung. Am. Rev. Respir. Dis., 118: 987 (1978).

5. De Troyer, A., Yernault, J. C., and Rodenstein, D.: Effects of vagal blockade on lung mechanics in normal man. J.. Appl. Physiol., 46: 217 (1979).

6. Douglas, N. J., Sudlow, M. F., and Flenley, D. C.: Effect of an inhaled atropinlike agent on normal airway function. J. Appl. Physiol., 46: 256 (1979).

7. Drazen, J. M., Loring, St. H., Jackson, A. C., Snapper, J. R., and Ingram. J. R. Effects of volume history on airway changes induced by histamine or vagal stimulation. J. Appl. Physiol., 47: 657 (1979).

8. Ekwo, E., and Weinberger, M.: Evaluation of a program for the pharmacologic management of children with asthma. J. Allergy Clin. Immunol., 6I: 240 (1978).

9. Geubelle, F.: The pulmonary provocation tests in asthmatic children. Proc. Int Congr. Allergy, 48, (1964).

10. Geubelle, F.: Contribution à L'étude Fonctionelle du Pumon de L'enfant Sain et de L'enfant Asthmatique. (J. Duculot SA, Gembloux, 1966).

11. Geubelle, F., and Breny, H.: Volumes pulmonaires de filles et de garçons sains agés de 5 à 6 ans. Poumon Coeur, 25: 1051 (1969).

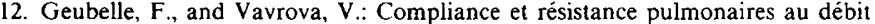
aérien chez l'enfant sain. Poumon Coeur, 25: 1085 (1969).

13. Geubelle, F., and Hofmann, D.: Diagnostische Möglichkeiten beim AsthmaSyndrom im Kindesalter. Meschr. Kinderheilk, 119: 233 (1971).

14. Geubelle, F., and Mossay, Chr.: Beta-mimetic agents and bronchodilator drugs in children. Acta Paediatr. Belg., 32: 79 (1979).

15. Hofmann, D., and Geubelle, F.: Forced vital capacity and total pulmonary flow resistance. (European Paediatric Respiratory Club, Nancy, 1973).

16. Hofmann, D., Geubelle, F.: Die Sekundenkapazität und der Lungengesamtwiderstand bein Kindern mit Asthmasyndrom. Helv. Paediatr. Acta, 29: 269 (1974).

17. Hogg, J. C.: The effects of lung growth on the distribution of airways resistance. In: R. Porter, J. Birch: Identification of Asthma. (Churchill Livingston, Edinburgh, 1971).

18. Ingram, H. R., Jr., Wellmann, J. J., McFadden, E. R., Jr., and Mead, J.: Relative contribution of large and small airways to flow limitation in normal subjects before and after atropine and isoproterenol. J. Clin. Invest., 59: 696 (1977).

19. Jones, R. L., Overton, Th. R., and Sproule, B. J.: Frequency dependence of ventilation distribution in normal and obstructed lungs. J. Appl. Physiol., 42: 548 (1977).

20. Kraemer, R., Geubelle, F.: Interdependence of lung conductance from static recoil and actual lung volume in normal and asthmatic children. Proceedings of the European Paediatric Respiratory Club, Nottingham/Cambridge, 1979.

21. Kraemer, R., Geubelle, F. (1980): Bronchial distensibility in asthmatic children. Annual meeting of the European Society for Paediatric Research, June 1-4, 1980, Athens, Greece. J. Pediatr. Res., 14: 1415 (1980).

22. Larsen, G. L., Barron, R. J., Cotton, E. K., and Brooks. J. G.: A comparative study of inhaled atropine sulfate and isoproterenol hydrochloride in cystic fibrosis. Am. Rev. Respir. Dis., 119: 399 (1979)

23. Leaver, D. G., Tattersfield, A. E., and Pride, N. B.: Contributions of loss of lung recoil and of enhanced airway collapsibility to the airflow obstruction of chronic bronchitis and emphysema. J. Clin. Invest., 52: 2117 (1973).

24. Leifer, K. N., and Wittig, H. J.: The beta $a_{2}$-sympathomimetic aerosols in the treatment of asthma. Ann. Allergy, 35: 69 (1975).

25. McFadden, E. R., Jr., Ingram, R. H., Haynes, R. L., and Wellmann, J. J.: Predominant site of flow limitation and mechanisms of postexertional asthma. J. Appl. Physiol., 42: 746 (1977).

26. Mills, R. J., Cumming, G., and Harris, P.: Frequency-dependent compliance at different levels of inspiration in normal adults. J. Appl. Physiol., 18: 1061 (1964).

27. Milner, A. D., and Ingram, D.: Bronchodilator and cardiac effects of isoprenaline, orciprenaline and salbutamol aerosols in asthma. Arch. Dis. Child.. 46: 502 (1971).

28. Müller-Wening, W., von der Hardt, H., and Wenner, J.: Die Wirkung subkutan injiziereter Terbutalins bei provozierter Bronchusobstruktion im Rahmen der inhalativen Allergentestung. Meschr. Kinderheilk, 125: 536, (1977).

29. Offermeier, J., Dreyer, A. G., Brandt, H. D., and Steinberg. S.: The $\beta_{2}$-selectivity of various $\beta_{2}$-adrenergic drugs. Med. Proc., 18: 5 (1972).

30. Pang, L. M., Rodriguez-Martinez, F., and Davis, W. J.: Terbutaline in the treatment of status asthmaticus. Chest, 72: 469 (1977).

31. Petit, J. M.: Physiopathologie de la dyspnée chez l'asthmatique. (Arcia, Bruxelles, 1965).

32. Posey, W. C., and Tinkelman, D. G.: Dose-response characteristics of nebulized isoproterenol in asthmatic children. J. Allergy Clin. Immunol., 63: 258 (1979).

33. Ritchie, D., Erben, A., McLennon, L. Landau, L. I., and Phelan. P. D.: Dose of terbutaline respirator solution in children with asthma. New Zeal. Med. J., 89: 332 (1979).

34. Roth, M. J., Wilson, A. F., and Novey, H. S.: A comparative study of the aerosolized bronchodilators, isoproterenol, metaproterenol and terbutaline in asthma. Ann. Allergy, 38: 16 (1972).

35. Trembath, P. W., Greenacre, J. K., Anderson, M., Dimmock, S., Mansfield, L., Wadsworth, M., and Green, M.: Comparison of four weeks treatment with fenoterol and terbutaline aerosols in adult asthmatics. J. Allergy Clin. Immunol., 63: 395 (1979).

36. von der Hardt, H., Geubelle, F., and Hellweg, H.: Static and dynamic lung compliance in asthmatic symptomfree children. Respiration, 33: 349 (1976).

37. von der Hardt, H., and Meister, W.: Allergentestung beim kindlichen Asthma bronchiale. Meschr. Kinderheilk, 123: 577 (1975)

38. von der Hardt, H.: Histaminprovokation (personal communication).

39. Walker, S. R., Evans, M. E., Richards, A. J., and Paterson, J. W.: The clinical pharmacology of oral and inhaled salbutamol. Clin. Pharmacol. Ther.. 13: 861 (1973).

40. Woolcock, A. J., and Read, J.: Improvement in bronchial asthma not reflected in forced expiratory volume. Lancet 2: 1323 (1965).

41. Woolcock, A. J.. Vincent, N. J., and Macklem. P. T.: Frequency dependence of compliance as a test for obstruction in the small airways. J. Clin. Invest., 48: 1097 (1969).

42. Zimmermann, I., Walkenhorst, W., and Wulmer. W. T.: The side of action of bronchodilating drugs ( $\beta_{2}$-stimulators) on antigen-induced broncho constriction. Respiration, 38: 65 (1979). 
43. The authors thank Mrs. J. Penning for the technical assistance. Mr. J. Green for the help in performing the English text. and Miss M. Stoller for the preparation of this manuscript.

44. Requests for reprints should be addressed to: R. Kraemer. M.D.. Department of Paediatrics, University of Berne. Inselspital. CH-3010 Berne. Switzerland.
45. This research was supported by grants from the University of Liege and the Swiss National Science Foundation. 78 BE 01.

46. Received for publication October 15, 1980.

47. Accepted for publication March 12, 1981

Copyright (C) 1981 International Pediatric Research Foundation, Inc. 